\title{
Analysis of Domestic Waste Water Systems as a Sustainable Development Goals Achievement (SDGs) in Settlements in Bulak District, Surabaya City
}

\author{
Andri Deka Lisiadi, Rooslan Edy Santosa \\ Narotama University, Surabaya \\ dekaandri16@gmail.com
}

\begin{abstract}
Water is an essential substance for life because the body of living things mostlyconsists of water, except for living things in the form of seeds, and spores. Water used by humans undergoes changes in chemical and physical properties.The complex problem that is often overlooked by the government and society is domestic wastewater caused by population growth and building developments in the city of Surabaya. This study used an interview technique (with a questionnaire instrument) and observation interviews. From the results of direct observation and interviews found the number of families who have and use private latrines by 99 respondents and only one respondent who wearspublic toilet. $99.5 \%$ of respondents have sewerage and only $0.5 \%$ of respondents who do not have.

Keywords: Water, domestic waste, Surabaya
\end{abstract}

\section{INTRODUCTION}

The general assembly of the United Nations (UN) on 25 September 2015 and then in New York, USA, has officially endorsed the Agenda for Sustainable Development or Sustainable Development Goals (SDGs) as a global development deal. One SDGs goal is to ensure the availability, management of water and sustainable sanitation. Reflecting on the experience of many countries to achieve the MDGs, sanitation isonesector that is very difficult toreach the target. Indonesia itselfis still working hard to ensure the MDGs target for sanitation can be achieved. The latest data in 2014 mentioned the achievements of access to sanitation in Indonesia has reached 59.71\% and are optimistic that in 2015 the target of $62.41 \%$ will be achieved.

Based on the Ministry of Environment No. 112 of 2003 regarding the water quality standard of domestic waste, domestic waste water is waste water frombusinessorsettlementactivities (real estate), restaurants, office, commercial, apartments and dormitories, (Live, 2003) Domestic waste is divided into two categories:

1. Domestic waste water from the washing water, such asdetergents, oils and pesticides.

2. Liquid waste from the latrines, such as soap, shampoo, feces and urine.

Environmental Health Risk Assessment Study (EHRA) is a participatory study in District / City to understand the conditions of sanitation and hygiene facilities as well as societal attitudes at the household scale. The data generated can be utilized for the development of sanitation programs,

Analysis of Domestic Waste Water Systems as a Sustainable Development Goals Achievement (SDGs) in Settlements in Bulak District, Surabaya City

Andri Deka Lisiadi, Rooslan Edy Santosa 
including advocacy at the regency / city until the village.Data collected from the study will be used EHRA Working Group of the Regency / City as one of the ingredients to prepare a White Paper, the determination of risk areas and Sanitation Strategy in the Regency / City (Ministry of Health, 2014),

\section{RESEARCH LOCATION}

The research was conducted in the District of Bulak that includes areas Geographic Surabaya, which is part of the Territory of North Surabaya, with a height of \pm 4-12 meters above sea level and has 4 villages (Village KedungCowek, Village Bulak, Village Kenjeran and complex Kenjeran, as well as the Village Sukolilo).

\section{RESEARCH METHODS}

This research is qualitative and quantitative, qualitative research which aims to understand the areas studied, such as behavior, action, or describe and explain the quality of social influences that can not be described, and measured or described through quantitative approach.

Specifies the number of samples is a very important part to do research. In a study determining the sample size minimum EHRA can use the formula Slovin. The purpose of determining the type of samples used to determine estimates of the proportion of the population using the sample proportion. Slovin formula as follows:

$$
n=\frac{N}{1+N e^{2}}
$$

Where :

$$
\begin{array}{ll}
\mathrm{n} & =\text { Number of samples } \\
\mathrm{N} & =\text { Total population } \\
\mathrm{e} & =\text { Sampling error allowed }
\end{array}
$$

Bulak sub-district has a total population of 42978 inhabitants. With a degree of confidence on research by $90 \%$, then the error rate of $10 \%$. By using the formula slovin and with a margin of error of $10 \%$, showed the number of samples / respondents were required as many as 100 samples. 1 sub-district has 5 villages where is each village taken 8 RT RT retrieved every 5 samples / respondents and the overall total is 200 samples / respondents can be said that the data is valid.

\section{RESULTS AND DISCUSSION}

Based on the results of the EHRA Study conducted with interviews using questionnaires / questionnaires, the number of respondents in the age group $>45$ years old was at the highest position, namely $36.5 \%$ followed by ages $41-45$ by $15 \%$, then aged $36-40$ years with $18.5 \%$, age range $31-35$ years is $18 \%$, age $26-30$ years is $6.5 \%$, then age $21-25$ years is $2 \%$ and the lowest age $\leq 25$ years is $0.5 \%$.

Analysis of Domestic Waste Water Systems as a Sustainable Development Goals Achievement (SDGs) 


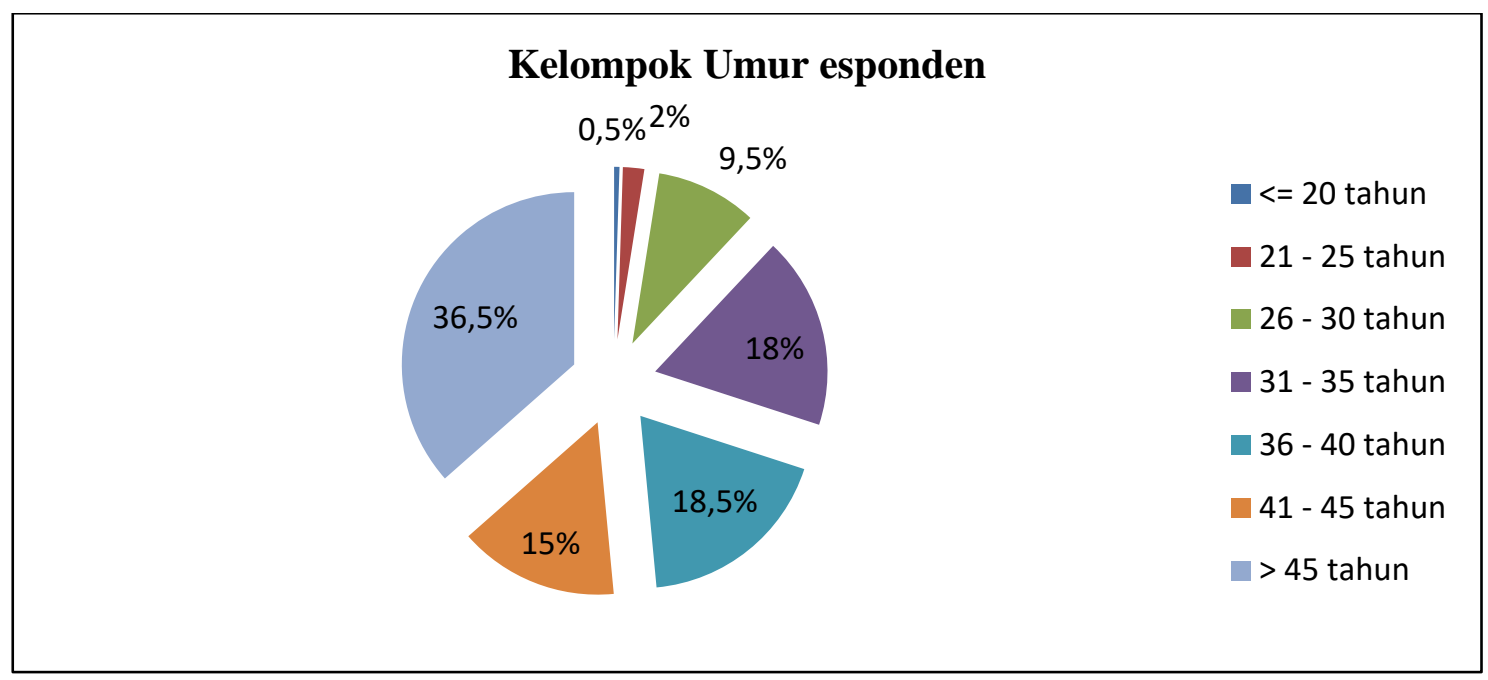

Picture 1. Respondents Age Group Ehra

EHRA Study Results also showed that the number of respondents to the status of their own homes and in the top position at $78 \%$ followed by belonging to the parents / children / siblings 14\%, the house with the status of contract by $3.5 \%$ and the balance status of the rental home, the home office and others only by $5 \%$. This is important information where the number of respondents with a high enough status in their own home will also affect the sense of sanitation infrastructure and facilities in the surrounding areas.

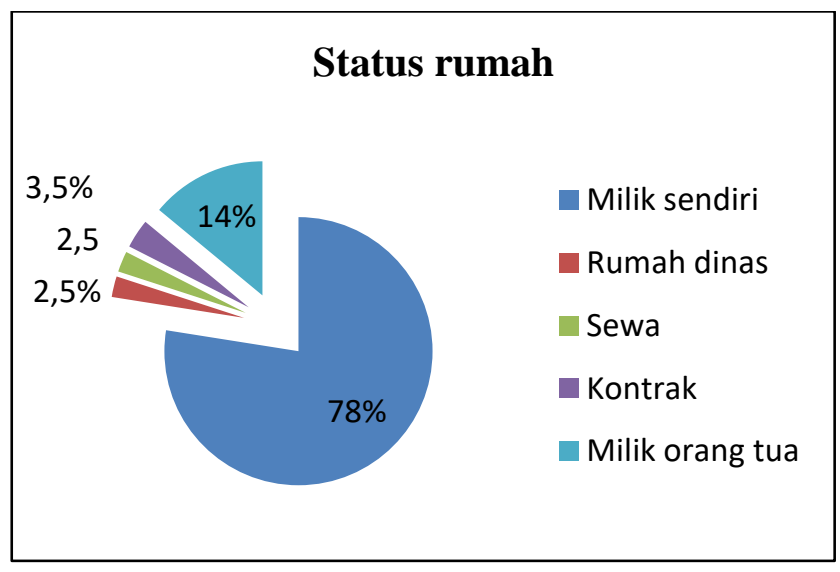

Picture 2. HomeStatus

Based on study results EHRA, the number of respondents with high school education last in the top position with $34 \%$ followed by the degree of the University / Academy of $19.5 \%$, amounting to $18 \%$ of junior high, elementary level $16.5 \%$, and respondents with low levels of education namely the level of vocational / Vocational $8.5 \%$. The above information explains that respondents with high school

Analysis of Domestic Waste Water Systems as a Sustainable Development Goals Achievement (SDGs) 
:: IJIEEB ::

(International Journal of Integrated Education, Engineering and Business)

Volume 1 Number 1 March 2018

This work is licensed under a Creative Commons Attribution-ShareAlike 4.0 International License.

education level or above had an impact on the understanding and awareness of the sanitation infrastructure and facilities available.

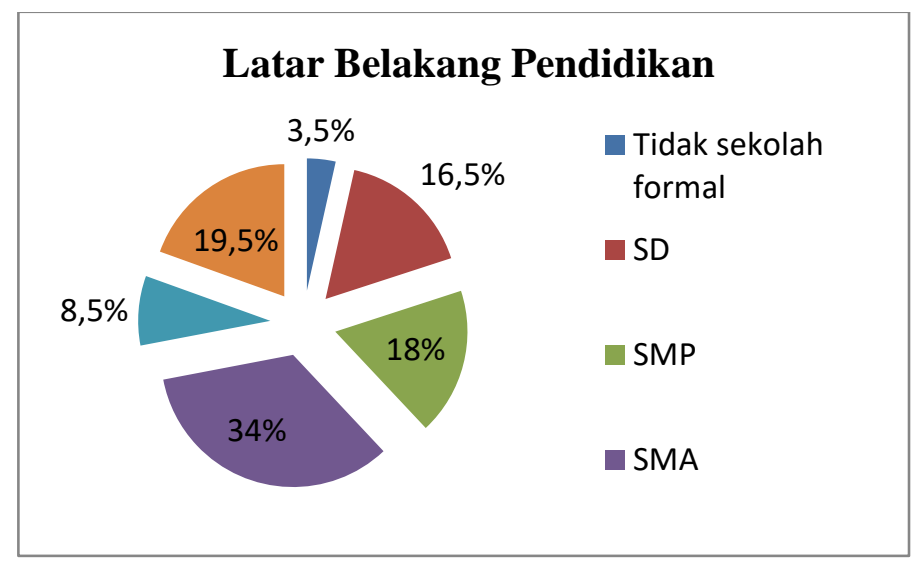

Picture 3. Educational background

In the EHRA Study referred to as a wastewater system is a system of distribution domestic waste from the rest of the bathroom waste, especially from the private latrine, public toilet and septic tank, as well as its relationship with the distribution system. Generally to be considered in the management of domestic waste water systems include sewage (Defecation). The practice of defecating in places inadequate is one risk factor for the decline in health status. In addition to such practices pollute the soil can contaminate ground water as a source of drinking water. Which is not adequate excreta disposal site is not just a place undue namely in the ditch, river, gardens,

Based on study results EHRA of $99.5 \%$ of respondents said defecating into a private latrine, $0.5 \%$ defecating into latrines /public toilet and by $100 \%$ stated not to defecate into a ditch or trench, and also at $100 \%$ claimed to not throw into pits, to the river / beach / ocean, and others.

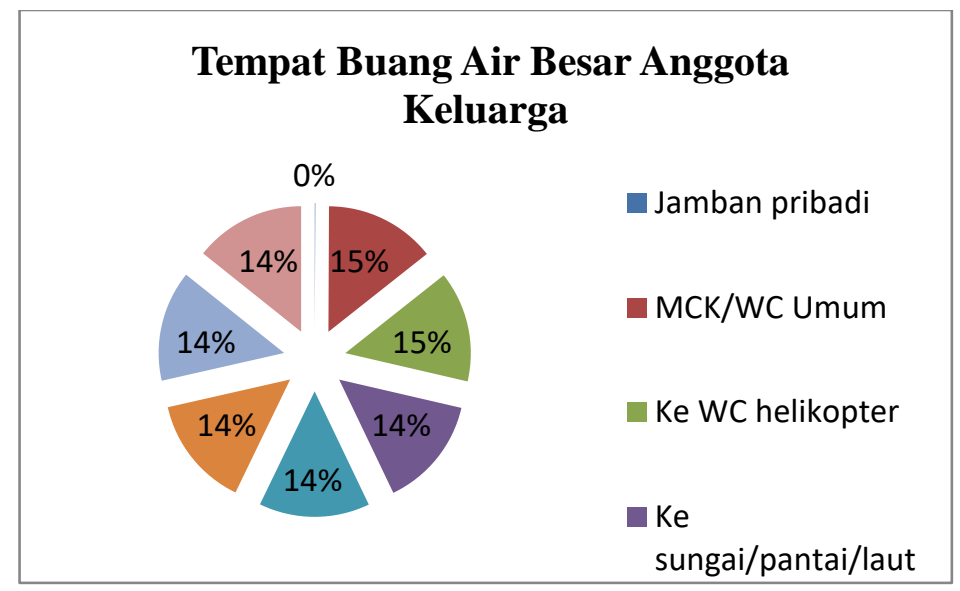

Picture 4.Defecation's place of Respondents

Analysis of Domestic Waste Water Systems as a Sustainable Development Goals Achievement (SDGs)

in Settlements in Bulak District, Surabaya City

Andri Deka Lisiadi, Rooslan Edy Santosa 
Based on the study results Ehra to defecate where family members of respondents EHRA by $66 \%$ of respondents have a Squat Toilet Goose Neck and the highest among other types followed Toilet Sitting Goose Neck Amounting to 33.5\% and the remaining 0.5\% to plengsengan. Therefore, the educational background also affects the type of toilet each respondent.

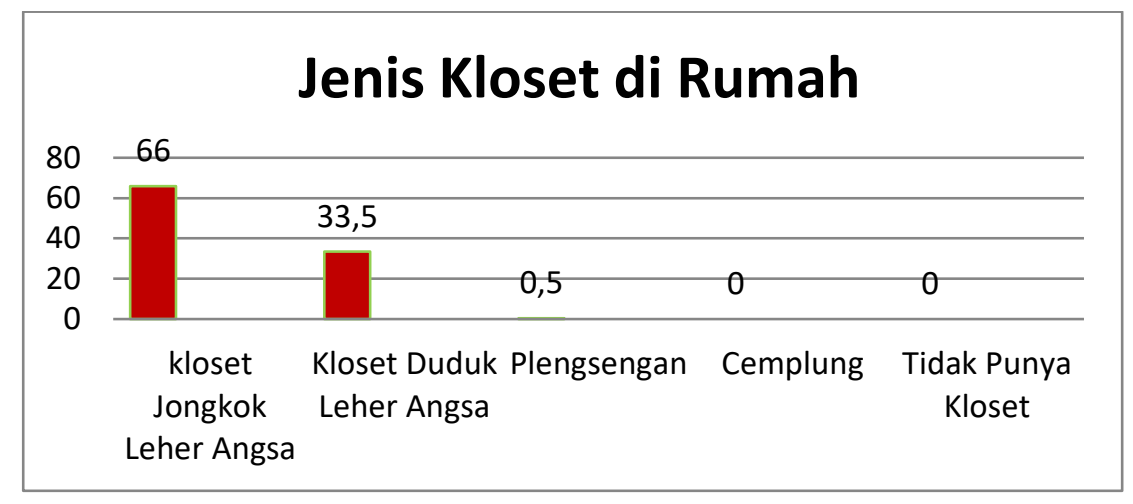

Picture 5. Respondents Toilet type Ehra

Based on study results EHRA by $98.5 \%$ of respondents perform final disposal of feces into the septic tanks, amounting to $1.5 \%$ discharged into the river / lake / beach, and no throw to direct drainage.

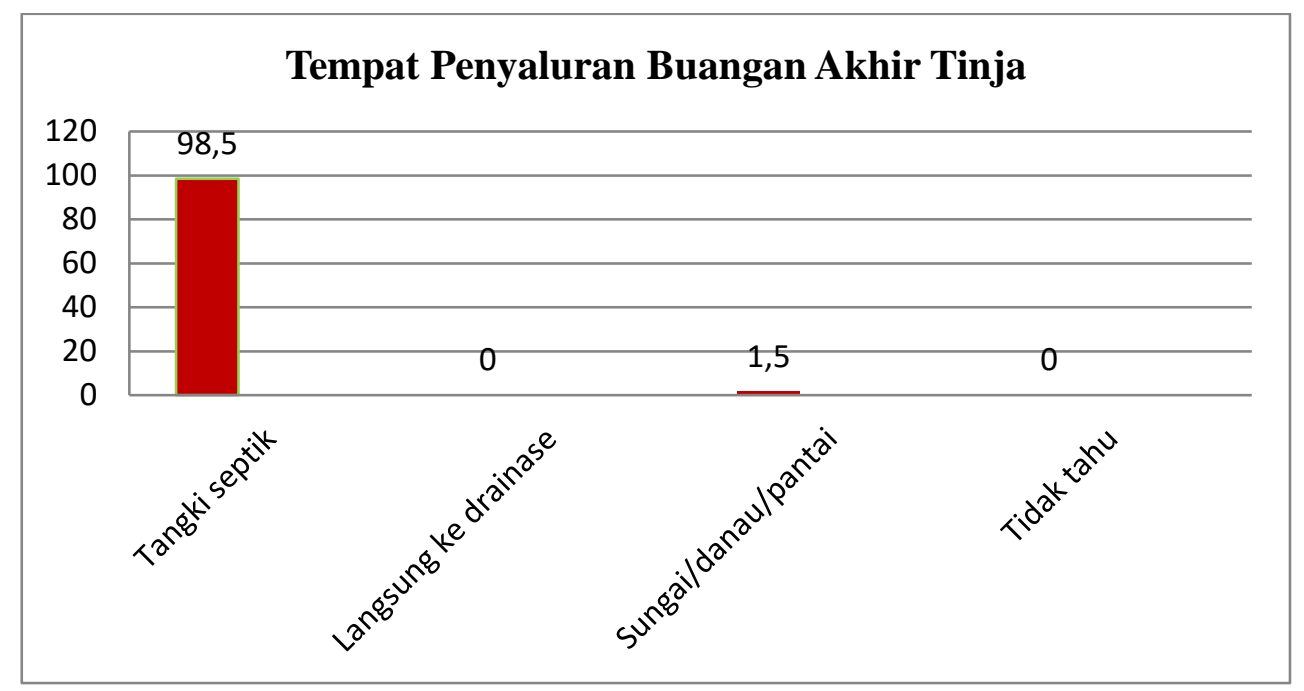

Picture 6. Distribution place of final effluent Feces

EHRA Study Results showed that $58.5 \%$ of septic tank built has been aged more than 10 years, $9 \%$ of respondents did not know when the septic tank was built, $24.5 \%$ of respondents stated that the existing septic tanks have been built since 5 - 10 years ago, people who said the septic tank was built in the 1-5 last year by $7.5 \%$ and the remaining states that the septic tank built $1-12$ months ago. This condition is very worrying because the cesspool created already more than 10 years ago had a greater possibility for leakage.

Analysis of Domestic Waste Water Systems as a Sustainable Development Goals Achievement (SDGs) in Settlements in Bulak District, Surabaya City

Andri Deka Lisiadi, Rooslan Edy Santosa 




Picture 7.Age of the Septic Tank

Based on the results Ehra study concluded that $98.5 \%$ of respondents who dump the sludge in the septic tank as much as 36\% never do depletion, depletion of 33\% perform between 1 and 5 years ago, $11.5 \%$ did not know if ever perform dewatering or not, $10.5 \%$ do depletion of more than 5-10 years ago by $6.5 \%$ perform dewatering between $0-12$ months ago, while $2.5 \%$ did the depletion of more than 10 years ago , this data is quite worrying for respondents who do emptying the septic tank is less than 5 years ago are still under $50 \%$ of respondents.

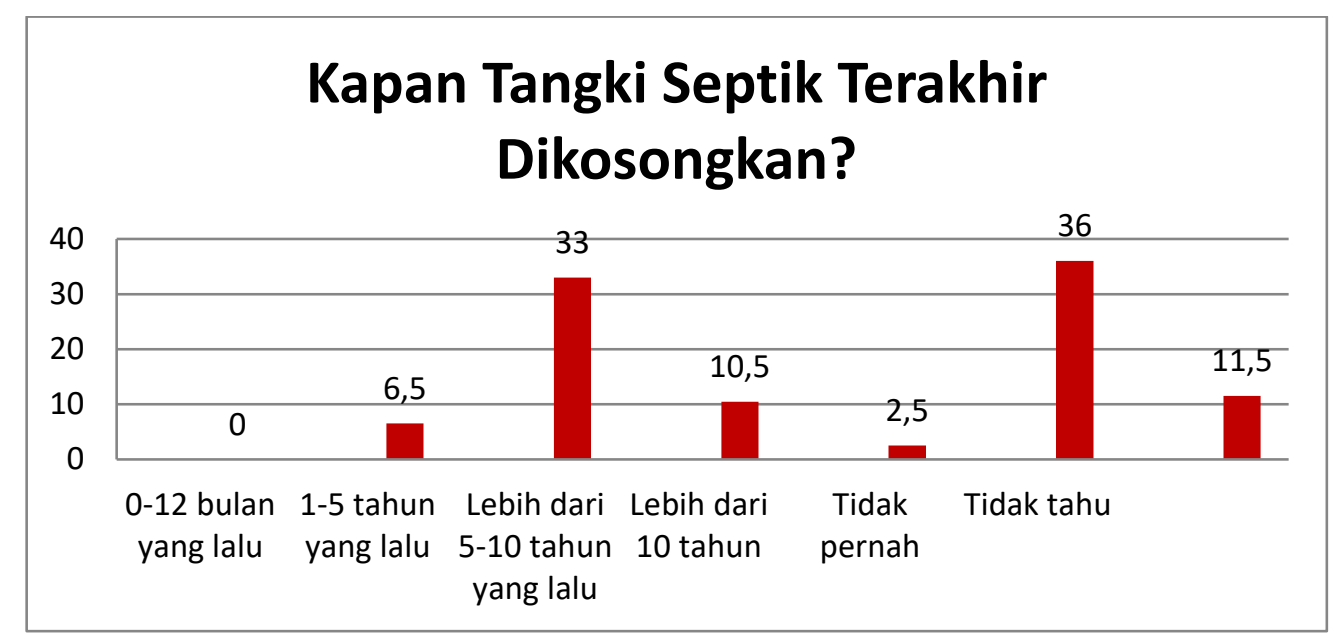

Picture 8. Septic tank emptied time

98.5\% of respondents who dump the sludge in the septic tank as much as $36 \%$ never do depletion, depletion of $33 \%$ perform between 1 and 5 years ago, $11.5 \%$ did not know if ever perform dewatering or not, at $10,5 \%$ do depletion of more than $5-10$ years ago by $6.5 \%$ perform dewatering between $0-12$ months ago, while $2.5 \%$ did the depletion of more than 10 years ago, this data is quite worrying because the respondent conducting drainage septic tank less than 5 years ago are still under $50 \%$ of respondents.

Analysis of Domestic Waste Water Systems as a Sustainable Development Goals Achievement (SDGs) in Settlements in Bulak District, Surabaya City

Andri Deka Lisiadi, Rooslan Edy Santosa 


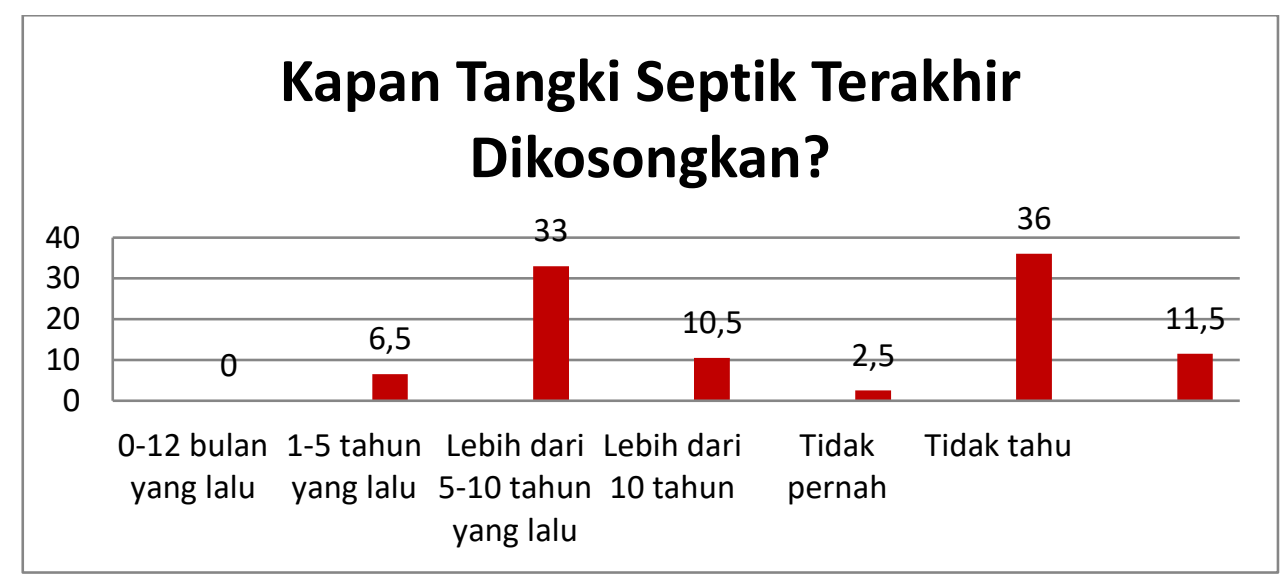

Picture 9. Septic tank emptied time

Based on studies related question EHRA where sludge disposed of at the time tangkiseptik emptied. which amounted to $50 \%$ of the respondents did not know where sludge was disposed of, amounting to $5.5 \%$ of respondents stated that the sludge discharged into rivers or streams, other $3 \%$, was buried in the yard by $3 \%$, while $1.5 \%$ stated buried land of others. This condition needs attention from the Surabaya City Government because respondents or many people did not know where the sludge should have been disposed of when the septic tank was emptied. Respondents who stated sludge dumped into rivers and streams is still quite high at $5.5 \%$, this is very disturbing cleanliness and health of the river water because of contamination of the sludge.

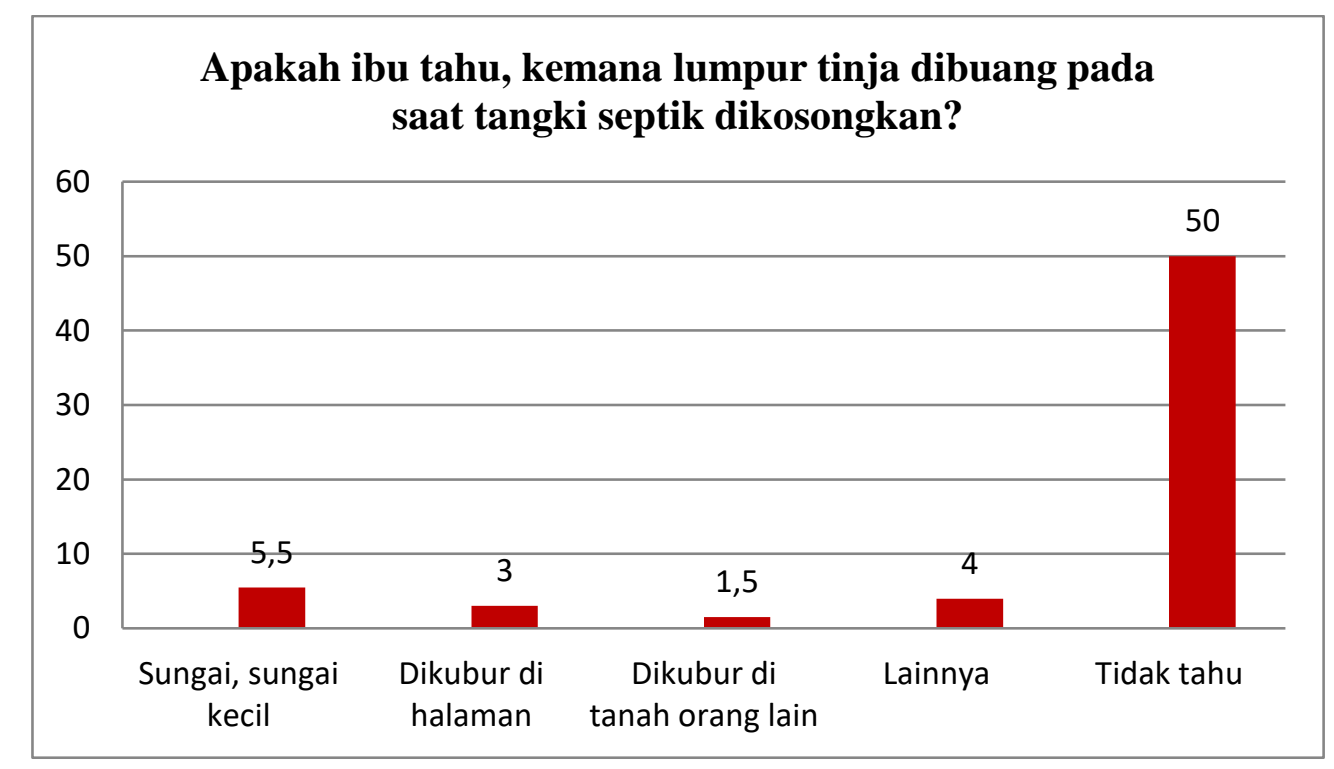

Picture 10. Septic tank emptied last time

Analysis of Domestic Waste Water Systems as a Sustainable Development Goals Achievement (SDGs) in Settlements in Bulak District, Surabaya City

Andri Deka Lisiadi, Rooslan Edy Santosa 
:: IJIEEB ::

(International Journal of Integrated Education, Engineering and Business)

Volume 1 Number 1 March 2018

This work is licensed under a Creative Commons Attribution-ShareAlike 4.0 International License.

200 number of respondents Ehra disposing of waste water coming from the kitchen dumped in a closed channel 115 respondents, followed by 89 respondents river / canal while open channels as much as 6 respondents and pipelines 2 respondents. Furthermore, most of the wastewater discharged came from the highest Bathroom disposed in a closed channel as much as 114 respondents followed in second place directly into the river / canal as much as 89 respondents and respondents 6 respondents disposed of open canals. Laundromats in place as much as 86 respondents dumped in the river / canal and the remaining 19 respondents disposed to several channels.

\section{CONCLUSION}

1. Domestic waste water management in District of Bulak Surabaya is dumping into the channel closed and open, street / yard pits, sewer pipes, pipe WWTP SANIMAS, and rivers / canals that means the system of domestic waste water in the district bulak is Processing System Local ( on Site System).

2. The majority of the citizens of District Bulak own private latrines and septic tanks are already making it means the people have managed to cope with all the risk of disease in public toilets, and hygiene and environmental health around.

\section{REFERENCES}

Eko, S. (2015). GUIDE SDGs, (November), jakarta. https://doi.org/http://dx.doi.org/10.1007/s11263008-0139-3.

Ministry of Health. (2014). Practical Guide to Implementation of the EHRA (Environmental Health Risk Assessment / Environmental Health Risk Assessment Due), 171.

Public health Office. (2015). Surabaya City Government Environmental Health Risk Assessment (Ehra).

Life, NYC (2003). Minister of Environment No. 112 of 2003 on Domestic Wastewater Quality Standard, 1-6. https://doi.org/10.1017/CBO9781107415324.004

Bulak sub-district in 2017. The Central Statistics Agency figures Surabaya BPS- Statistics of Surabaya Municipality. KecamataBulak. City of Surabaya.

Analysis of Domestic Waste Water Systems as a Sustainable Development Goals Achievement (SDGs)

in Settlements in Bulak District, Surabaya City

Andri Deka Lisiadi, Rooslan Edy Santosa 